\title{
Microstructure and Pitting Corrosion Resistance of Quenched, Single Tempered and Double Tempered AISI 420 Martensitic Stainless Steel
}

\author{
Cláudio Moreira de Alcântara ${ }^{a, c}$, Ariane Neves de Moura ${ }^{b *}$ (1), Marcos Tadeu D'Azeredo Orlando ${ }^{b}$ (†, \\ Wilian da Silva Labiaparic (1), Marco Antônio da Cunha ${ }^{c}$, Tarcísio Reis de Oliveira ${ }^{c}$,
}

Vicente Tadeu Lopes Buono ${ }^{a}$ (1)

\begin{abstract}
${ }^{a}$ Universidade Federal de Minas Gerais, Departamento de Engenharia Metalúrgica e de Materiais, Belo Horizonte, MG, Brasil.

${ }^{b}$ Universidade Federal do Espirito Santo, Programa de Pós-Graduação em Engenharia Mecânica, Vitória, ES, Brasil.

'Aperam South America Research Center, Timóteo, MG, Brasil.
\end{abstract}

Received: February 18, 2021; Revised: July 24, 2021; Accepted: September 6, 2021

\begin{abstract}
The crystallographic aspects after air-quenching treatment and the pitting corrosion resistance after single tempering and double tempering treatments of AISI 420 martensitic stainless steel were studied using optical microscopy, Electron Backscatter Diffraction and potentiodynamic polarization tests. The results showed that the observed average orientation relationship (OR) was closer to the Greninger-Troiano (G-T) OR model with a minimum average deviation of $2.66^{\circ}$. The average OR of AISI 420 steel with respect to austenite matrix was $\varphi_{1}=3.6^{\circ}, \Phi=46.0^{\circ}, \varphi_{2}=6.2^{\circ}$ in the area mapped. Blocks showed variant pairs belonging to the same Bain group forming sub-blocks with misorientation $5.51^{\circ}<\overline{6} \quad 011>$ (V1/V4 pair), consequently, the AISI 420 martensitic stainless steel showed higher intervariant boundary density for the same Bain group and close-packed plane group. In the same air-quenching condition, the different sizes of prior austenite grain in the microstructure did not influence the variant selection. The air-quenching and single tempering treatments did not impair the pitting corrosion resistance and did not cause significant loss of hardness in relation to the air-quenched treatment. Therefore, the double tempering should be dispensed saving production costs.
\end{abstract}

Keywords: Martensitic stainless steel, Orientation relationship, Greninger-Troiano, Pitting corrosion resistance.

\section{Introduction}

AISI 420 martensitic stainless steel is based on $\mathrm{Fe}-\mathrm{Cr}$ - $\mathrm{C}$ ternary system with $12-14 \% \mathrm{Cr}$ and $0.15 \% \mathrm{~min} \mathrm{C}$ and is applied in cutlery, valve parts, gears, shafts, and rollers ${ }^{1,2}$. The martensitic transformation is a displacive and athermal reaction in which the austenite phase shows crystalline structure and shape changes resulting in lath martensite microstructure with heterogeneities in multiple scales ${ }^{3-5}$. The characterization of lath martensite consists of investigating the microstructure and the crystallography, including variant selection and grain boundary misorientation ${ }^{6}$. The most usual OR models found in the literature are Kurdjumov-Sachs $(\mathrm{K}-\mathrm{S})^{7}$, Greninger-Troiano $(\mathrm{G}-\mathrm{T})^{8}$ and Nishiyama-Wasserman $(\mathrm{N}-\mathrm{W})^{9}$. The G-T and N-W ORs are close to K-S with a deviation of $2.7^{\circ}$ and $5.3^{\circ}$, respectively ${ }^{4}$. The study of ORs in martensitic steel fully transformed has been performed using the reconstructed austenite orientation and martensite orientation obtained by the Electron Backscatter Diffraction (EBSD) technique. This method provides a higher number of measurement points improving the statistical significance as

*e-mail: ariane.neves.moura@gmail.com compared with transmission electron diffraction methods ${ }^{6,10-13}$. In addition, the representation of misorientation distribution functions in Euler space has shown greater accuracy when compared to pole and inverse pole figures ${ }^{14,15}$.

The determination of OR that describes the martensitic transformation in steels is essential to the characterization of block and sub-block boundary misorientations, consequently, the mechanical properties ${ }^{12,16,17}$. The intervariant misorientation angle/axis pairs are specific for each $\mathrm{OR}^{18,19}$. Additionally, the reconstruction is improved by the selection of appropriate OR, consequently, better information about microstructure, grain size and orientation of the austenite phase is obtained ${ }^{11,20}$.

In general, the tempering process is carried out to increase the ductility and toughness since the quenching condition of martensitic stainless steel is brittle. The decrease of the dislocation density and nucleation and growth of carbides occur during the tempering, which influences the pitting corrosion resistance. At temperatures lower than $350^{\circ} \mathrm{C}$, the carbon from the matrix combines with the iron atoms to form $\mathrm{M}_{3} \mathrm{C}$ carbides due to the reduced $\mathrm{Cr}$ diffusivity ${ }^{21-27}$. It has been reported that the $\mathrm{M}_{3} \mathrm{C}$ carbides with plate shape 
(40-50 nm in thickness) and orthorhombic or hexagonal structure precipitate between the martensitic laths ${ }^{22}$.

The corrosion resistance of tempered martensitic stainless steel in the range of $300^{\circ} \mathrm{C}-700^{\circ} \mathrm{C}$ has been extensively studied $^{21-26}$. However, the AISI 420 martensitic stainless steel is quenched and tempered or double tempered at temperatures up to $250^{\circ} \mathrm{C}$ in the case of cutlery application. In addition, to the best of our knowledge, there are no investigations in the literature regarding the OR that describes the martensitic transformation in stainless steel. In this context, the objective of the current study was to characterize the martensitic microstructure of AISI 420 steel after the air-quenching process. Particular attention was paid to the determination of orientation relationship and crystallographic analysis in addition to the corrosion resistance dependence with the single and double tempering processes at $180^{\circ} \mathrm{C}$ simulating the industrial process.

\section{Material and Methods}

The material used in this work was AISI 420 martensitic stainless steel with a chemical composition of $0.19 \% \mathrm{C}$, $12.1 \% \mathrm{Cr}, 0.09 \% \mathrm{Ni}, 0.25 \% \mathrm{Mn}, 0.41 \% \mathrm{Si}, 0.01 \% \mathrm{P}$ and $0.001 \% \mathrm{~S}$. The heat treatments consist of air-quenching, single tempering and double tempering. The samples were austenitized at $1050^{\circ} \mathrm{C}$ for $5 \mathrm{~min}$ in a muffle furnace followed by air cooling. Subsequently, the air-quenched samples were tempered at $180^{\circ} \mathrm{C}$ for two hours followed by air cooling (single tempering). The double tempering was performed under the same conditions as the single tempering.

The air-quenched, single tempered and double tempered samples were examined by optical microscopy on a longitudinal section using Villela and Groesbecker etchings. Standard procedures were applied in the sample preparation. The EBSD analysis was performed on a field emission gun FEI Quanta 250 scanning electron microscope equipped with EDAX system. The step size was $0.20 \mu \mathrm{m}$. The kernel average misorientation (KAM) was calculated using 5 neighbors with a maximum misorientation angle of $5^{\circ}$.

The prior austenite grains were reconstructed using the ARPGE (Automated Reconstruction of Parent Grains from EBSD data) software developed by Cayron ${ }^{28}$. The data points that have a confidence index $(\mathrm{CI})<0.095$ were removed. The neighbor CI correlation was used to put in contact the neighboring grains. The parent grain reconstruction is performed in two steps namely nucleation and growth of parent grains. The tolerance angle employed for daughter grain identification was $3^{\circ}$ based on the minimum misorientation between variants of $5.51^{\circ}$ in the G-T OR. In the first step, the identification of the nuclei is carried out by misorientation between four (quadruplet) adjacent daughter grains with the theoretical operators ${ }^{28}$. The tolerance for parent grain

Table 1. ORs between face centered cubic and body centered cubic crystals.

\begin{tabular}{cccc}
\hline \multirow{2}{*}{ OR } & \multicolumn{3}{c}{ Euler angles $\left(^{\circ}\right)$} \\
\cline { 2 - 4 } & $\varphi_{1}$ & $\Phi$ & $\varphi_{2}$ \\
\hline K-S & 5.77 & 48.19 & 5.77 \\
\hline G-T & 2.7 & 46.6 & 7.5 \\
\hline N-W & 0 & 45 & 9.73 \\
\hline
\end{tabular}

nucleation was $3^{\circ}$. According to Cayron ${ }^{28}$, the tolerance can range from $3^{\circ}$ to $5^{\circ}$. Then, the growth of the nucleus is conducted by calculating and comparing the misorientation inside this nucleus and the neighboring grains with the theoretical operators increasing the tolerance angle up to $15^{\circ 28}$. Table 1 shows the Euler angles for the K-S, G-T and $\mathrm{N}-\mathrm{W}$ ORs selected in ARPGE.

The misorientation between the orientations of reconstructed austenite grains and martensite orientations was determined using a compute routine in MTEX software developed by Almeida et al. ${ }^{15,29}$. The routine calculates the 576 equivalent misorientations in the face centered cubic (FCC) to body centered cubic (BCC) transformation and selects the misorientations that correspond to the reduced Euler space delimited by $0^{\circ}<\varphi_{1}<10^{\circ}, 40^{\circ}<\Phi<50^{\circ}$ and $0^{\circ}<\varphi_{2}<10^{\circ}$, which contains one variant of each OR model selected ${ }^{15}$.

The average OR for all data collected was calculated through the mean angular deviation $\left(\Delta \theta_{\text {average }}\right)$ according to Equation (1):

$$
\Delta \theta_{\text {average }}=\sum_{N} \Delta \theta_{i} / N
$$

where $\mathrm{N}$ is the number of pixels and $\Delta \theta_{\mathrm{i}}$ is misorientation between the experimental misorientation in the FCC to BCC transformation and selected OR model in the ARPGE ${ }^{10,11}$. The MTEX software was also employed in the crystallographic analysis. In addition, this software was used to plot the pole figures according to the G-T OR model and average OR of the present study.

Potentiodynamic polarization tests were performed using a conventional three-electrode set-up comprising a graphite as counter electrode (CE), a saturated calomel electrode (SCE) as the reference electrode (RE) and the sample prepared as the working electrode (WE) in aerated $3.5 \mathrm{wt} \% \mathrm{NaCl}(\mathrm{pH}=6)$ solution. The samples were ground up to \#600 using SiC papers and ultrasonically cleaned. The electrochemical measurements were repeated twice for each sample. The hardness was determined using Wolpert 930 Instron durometer in accordance with ASTM E8 $\operatorname{standard}^{30}$.

\section{Results and Discussion}

The microstructures of the samples after air-quenching, single tempering and double tempering treatments are shown in Figure 1. The AISI 420 showed martensitic microstructure with $\mathrm{M}_{23} \mathrm{C}_{6}(\mathrm{M}=\mathrm{Fe}, \mathrm{Cr})$ carbides after air-quenching treatment. The austenitization process at $1050^{\circ} \mathrm{C}$ for $5 \mathrm{~min}$ did not cause the complete dissolution of $\mathrm{M}_{23} \mathrm{C}_{6}$ carbides formed during the hot rolling process. The amount of $\mathrm{M}_{23} \mathrm{C}_{6}$ carbides is reduced with increasing in the austenitization temperature ${ }^{27,31,32}$. After single tempering and double tempering treatments, the undissolved $\mathrm{M}_{23} \mathrm{C}_{6}$ carbides during the air-quenching treatment remained in the martensitic matrix as expected. In addition, the fraction also remained constant in a qualitative approach due to low tempering temperature. The nucleation and growth of $\mathrm{M}_{23} \mathrm{C}_{6}$ carbides is a diffusion-controlled process occurring at temperatures higher than $500^{\circ} \mathrm{C}$ during tempering ${ }^{21-26}$. The hardness values were 47.7 (0.2) HRC, 47.3 (0.2) HRC and 46.3 (0.1) HRC for the samples after air-quenching, single 

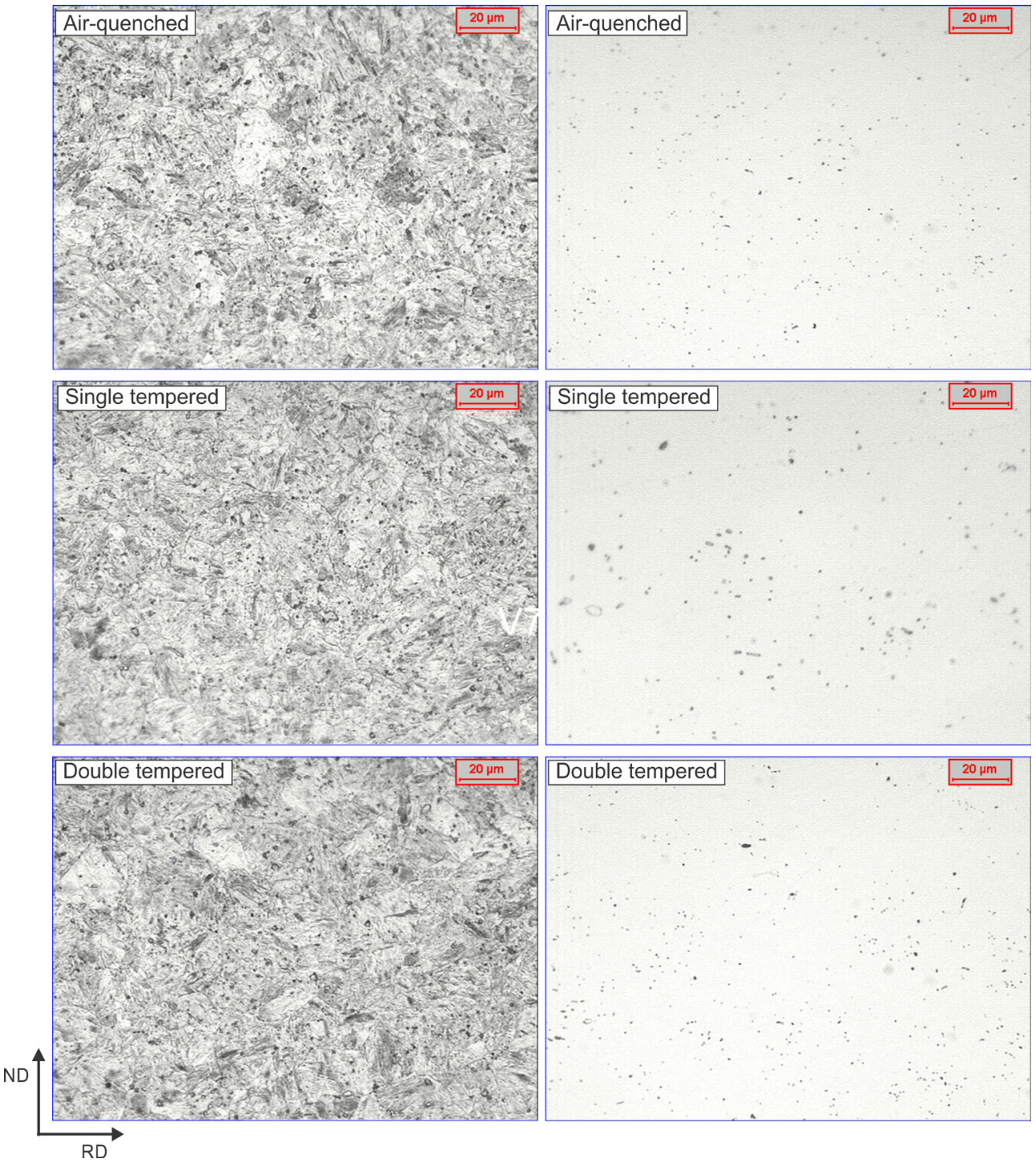

Figure 1. Microstructure of the samples after air-quenching, single tempering and double tempering treatments. Left-hand side: Villela etching. Right-hand side: Groesbecker etching.

tempering and double tempering treatments, respectively. Calliari et al. ${ }^{33}$ reported that the hardness decreases with tempering temperatures higher than $200^{\circ} \mathrm{C}$ for AISI 420 with $0.19 \% \mathrm{C}, 12.90 \% \mathrm{Cr}, 1.0 \% \mathrm{Ni}$ and $1.7 \% \mathrm{Mo}$.

The microstructure of air-quenched AISI 420 steel analyzed by EBSD is shown in Figure 2, where the inverse pole figure (IPF) map and grain boundary map superimpose the corresponding image quality map. Figure 2 also brings the misorientation angle distribution. From Figure 2a, it can be observed that the microstructure consisted of parallel or near parallel laths groups forming blocks and packets as described by Morito et al..$^{34,35}$ and Kitahara et al. ${ }^{36}$. In addition, several prior austenite grains can be distinguished in the microstructure. The prior austenite grains are divided into several packets and each packet is subdivided into blocks. The packets are laths groups that have the same habit plane and the blocks are lath groups with the same variant orientation ${ }^{34-36}$. The distribution exhibited two main peaks at low $\left(2^{\circ}-10^{\circ}\right)$ and high $\left(55-63^{\circ}\right)$ misorientation angles, which were intervariant misorientation angles (Figure 2c). In addition, there was a third peak at $53.7^{\circ}$ misorientation angle. The low fraction (0.062) of misorientation angles between $20^{\circ}$ and $50^{\circ}$ corresponded to austenite grain boundaries. Prior austenite grain boundaries were distinguished in Figure $2 b$ by black lines (misorientation above $20^{\circ}$ and below $50^{\circ}$ ) and the blocks and packets grain boundaries by yellow lines (misorientation above $9^{\circ}$ and below $20^{\circ}$ and higher than $50^{\circ}$ ).

Figure 3 shows the reconstructed prior austenite grains for K-S, G-T and N-W ORs selected in ARPGE. It can be observed a deviation in the orientation of some grains; consequently, prior austenite grain average diameters also differ when the ORs are compared. The prior austenite grain average diameters were 24.5 (8.9) $\mu \mathrm{m}, 20.5$ (8.6) $\mu \mathrm{m}$ and $24.2(10.4) \mu \mathrm{m}$ for K-S, G-T and N-W ORs, respectively. The prior austenite grain boundaries in all reconstructed maps showed serrated morphology, which is related to common 

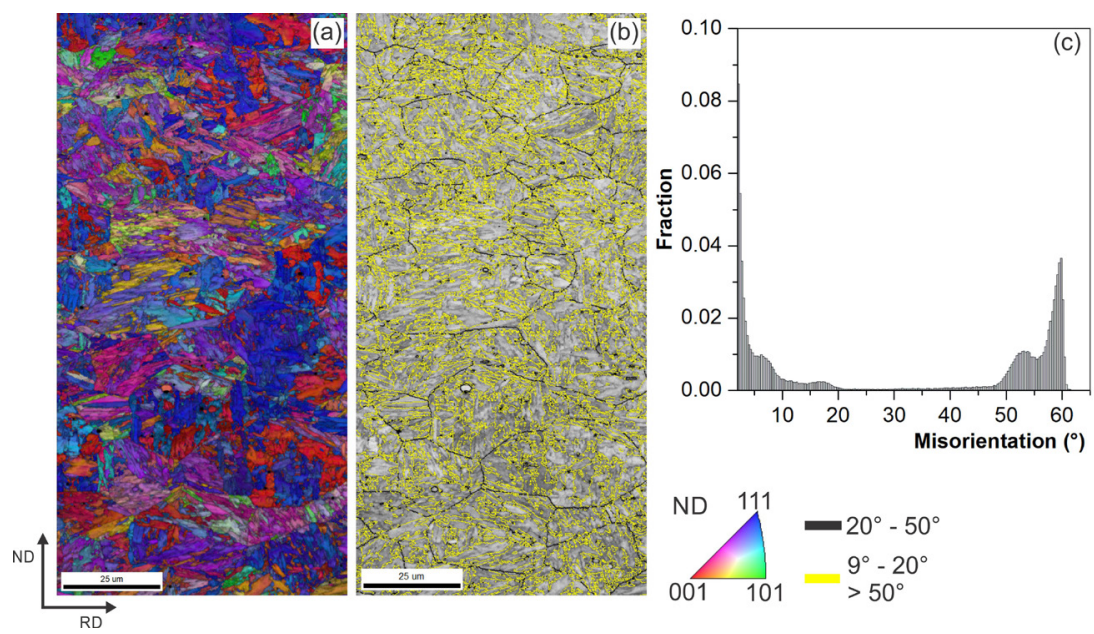

Figure 2. Sample after air-quenching treatment: (a) inverse pole figure (IPF) map and (b) grain boundary map superimpose the corresponding image quality map and (c) misorientation angle distribution.
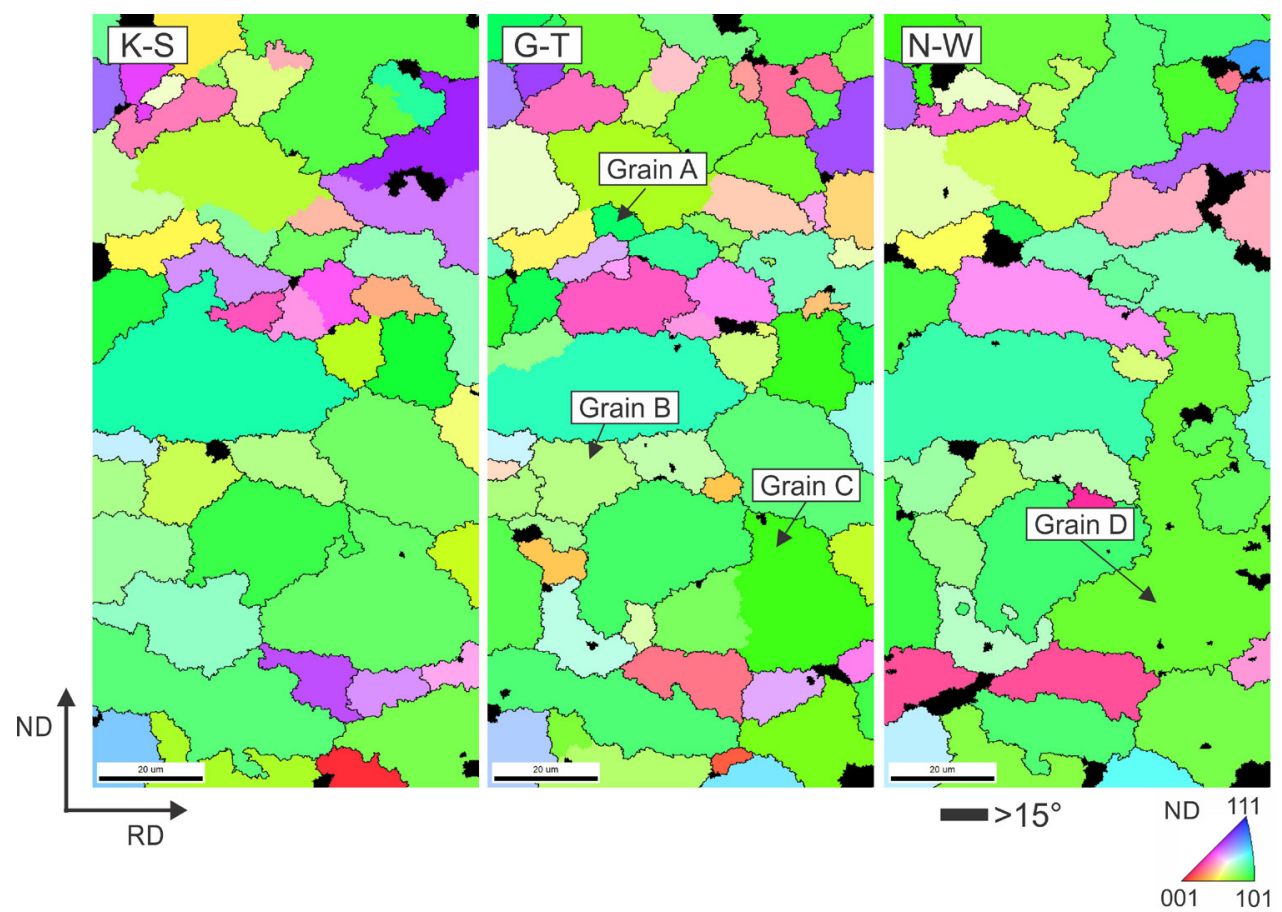

Figure 3. Sample after air-quenching treatment: reconstructed prior austenite grains for K-S, G-T and N-W ORs selected in ARPGE.

and small activated variants for neighboring grains ${ }^{15}$. The reconstructed fractions were $0.97,0.97$ and 0.95 for K-S, G-T and N-W ORs, respectively. The non-reconstructed area has been related to the insufficient number of variants of small prior austenite grains that make the reconstruction more complex. In addition, the uncertainty degree of the reconstruction is increased by the refinement of prior austenite grain size ${ }^{37}$. The lowest area reconstructed corresponded to $\mathrm{N}-\mathrm{W}$ OR. It was found a grain incorrectly reconstructed using N-W OR indicated as grain D in Figure 3, suggesting reduced accuracy in the reconstruction. Back to Figure 2, grain boundaries between $20^{\circ}$ and $50^{\circ}$ can be seen dividing this reconstructed grain. As stated in Refs ${ }^{11}$ and $^{20}$, the OR selected significantly affects the quality of the reconstruction.
Figure 4 shows the misorientation distribution between the martensite and prior austenite reconstructed using K-S, G-T and N-W ORs represented in a reduced Euler space. The angular deviation distributions between misorientations and the respective ORs models according to Eq (1) are shown in Figure 5. The misorientation showed high intensity close to G-T OR. The OR selected in the reconstruction affects the misorientation distribution in the reduced Euler space ${ }^{15}$. The $\Delta \theta_{\text {average }}$ were $3.97^{\circ}, 2.66^{\circ}$ and $4.12^{\circ}$ for K-S, G-T and N-W ORs models, respectively. Therefore, it can be concluded that the average OR of AISI 420 was closer to G-T OR model. The average OR of AISI 420 with respect to austenite matrix was $\varphi_{1}=3.6^{\circ}, \Phi=46.0^{\circ}, \varphi_{2}=6.2^{\circ}$ based on the misorientation distribution between the martensite and prior austenite 

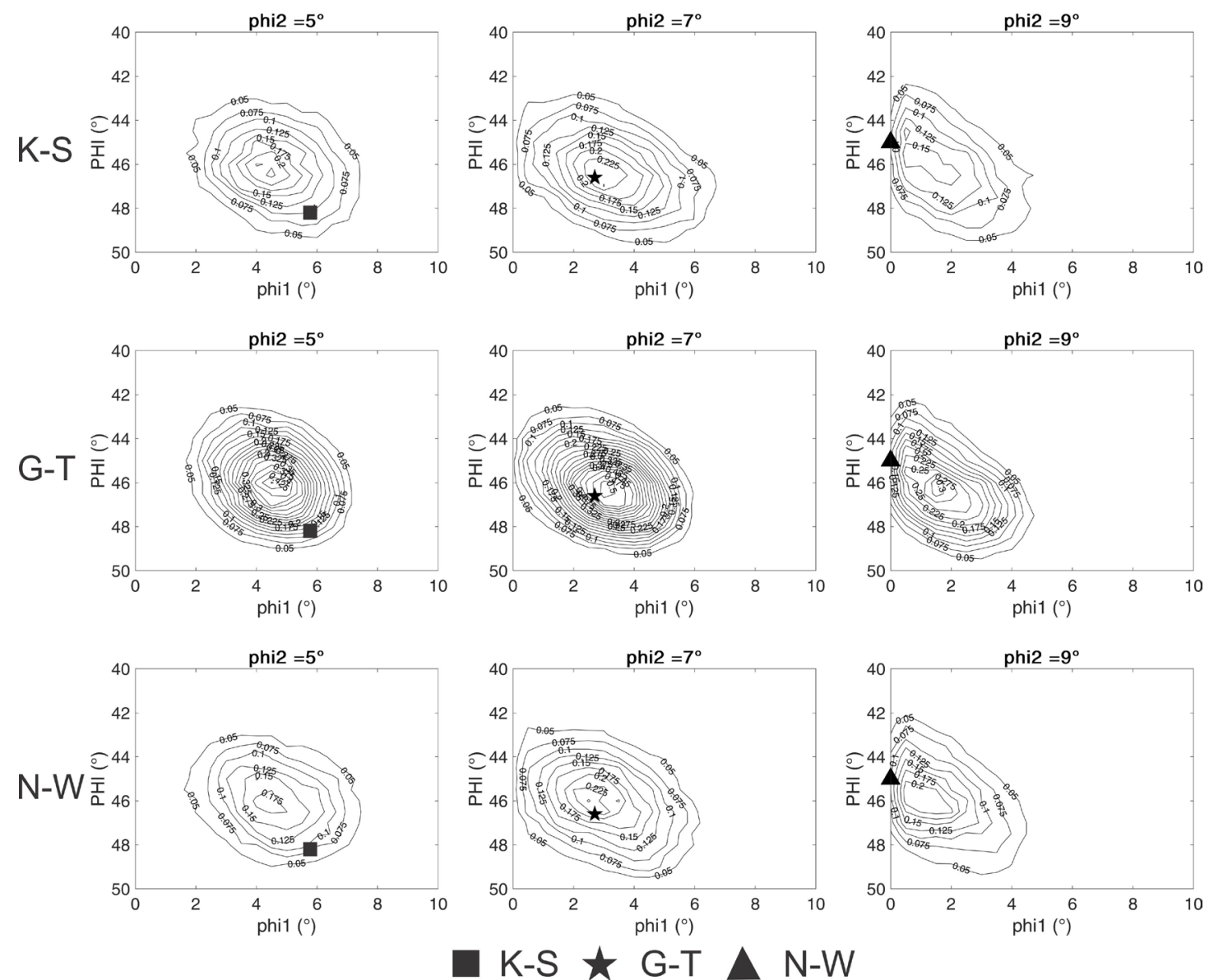

Figure 4. Sample after air-quenching treatment: misorientation distribution between the martensite and prior austenite reconstructed using K-S, G-T and N-W ORs.

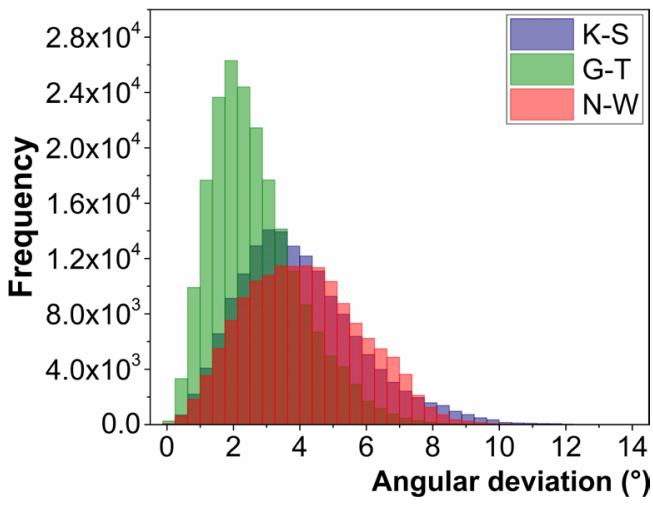

Figure 5. Sample after air-quenching treatment: angular deviation distributions between misorientations and the respective theoretical ORs.

reconstructed using G-T OR model of the area mapped. The increase of $\Delta \theta_{\text {average }}$ causes the degradation of reconstruction which explains the lowest area reconstructed and a probably grain incorrectly reconstructed observed when the N-W OR was selected, as mentioned above (Figure 3$)^{11}$. It has been reported that the OR in steels shows a degree of scattering around the OR models since the OR can vary from one grain to another ${ }^{18,19,36}$. The austenite and transformed martensite are plastically deformed to accommodate the shape strain during martensitic transformation, consequently, the orientations of both phases are rotated causing the scattering around the OR models observed ${ }^{11,18,19}$.

Figure 6 shows the 24 martensite variants considering that the prior austenite orientation is (001)[100] for the G-T OR model and the average OR of AISI 420. Table 2 provides the angle-axis misorientations taking variant 1 as the reference calculated according to the G-T OR model and the average OR of AISI 420. Note that the minimum misorientation between variants of the same Bain group and different blocks or packets were $5.02^{\circ}$ and $11.21^{\circ}$, respectively, in the G-T OR model. The Bain groups are defined based on the compression direction of austenite phase during the Bain strain ${ }^{6}$. The compression along the $\mathrm{z}$-axis, $\mathrm{x}$-axis and $\mathrm{y}$-axis was labeled $\mathrm{B} 1, \mathrm{~B} 2$ and $\mathrm{B} 3$ groups, respectively, in Figure 6 and Table 2. The close-packed plane (CP) groups are formed by six variants that have the same close-packed plane with the austenite (CP1: (111), CP2: (1 $\overline{1} 1)$, CP3: ( $\overline{1} 11)$ and CP4: $(11 \overline{1}))$. There are 16 possible angle-axis misorientations in G-T OR, which 13 angle-axis misorientations are higher than $15^{\circ}$; thus considered high angle grain boundaries. In the case of the average OR 
observed in the present study, the misorientation between $\mathrm{V} 1 / \mathrm{V} 4$ pair of the same Bain group increased $0.49^{\circ}$. The minimum misorientation between different blocks or packets (V1/V8 pair) decreased $2.15^{\circ}$ in relation to the G-T OR model. The intervariant misorientations are in agreement with the three peaks observed in the misorientation angle distribution (Figure 2b).

Based on Table 2, Figure 7 provides the intervariant boundary length density distributions (boundary length per unit area) taking variant 1 as the reference of the complete map. The distributions of the grains A, B and C (indicated Figure $3 \mathrm{~b}$ ) are also shown in Figure 7 . The deviation angle of $3^{\circ}$ was adopted to avoid a significant overlap of different intervariant grain boundaries. The diameter of the grains A, B and C were $8.16 \mu \mathrm{m}, 18.05 \mu \mathrm{m}$ and $32.20 \mu \mathrm{m}$, respectively. It should be mentioned that the three selected grains represent the complete area of the map. The grain boundary length density of V1/V4 pair that belongs to the Bain 1 was higher as compared with V1 and other variants for the complete map and the grains A, B and C. The variants

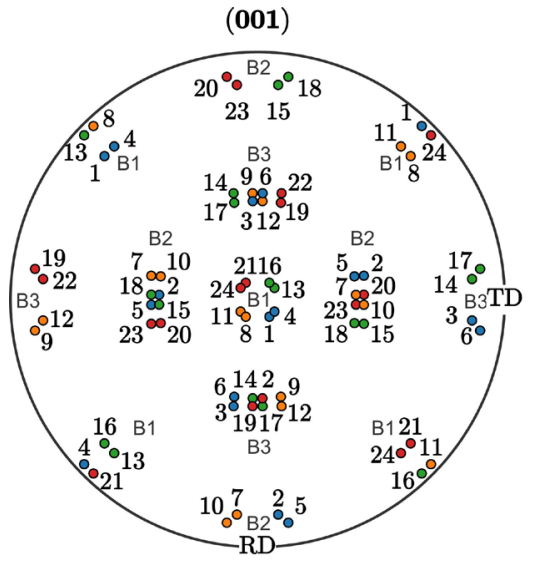

(a)

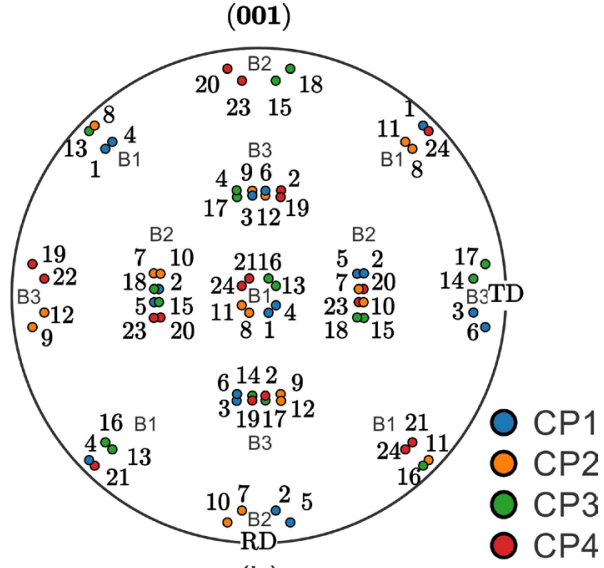

(b)

Figure 6. 24 martensite variants considering that the prior austenite orientation is (001)[100]: (a) G-T OR model and (b) average OR of AISI 420

Table 2. 24 variants of G-T OR model and the average OR of AISI 420.

\begin{tabular}{|c|c|c|c|c|c|c|c|}
\hline \multirow[b]{2}{*}{ Variants } & \multicolumn{5}{|c|}{ G-T OR model } & \multicolumn{2}{|c|}{ Present study } \\
\hline & $\begin{array}{r}\text { Close } \\
\mathrm{pl} \\
\end{array}$ & & Bain & Mis. angle from V1 & Rotation Axis in V1 & Mis. angle from V1 & Rotation Axis in V1 \\
\hline 1 & \multirow{6}{*}{ (111) } & \multirow[t]{6}{*}{ CP1 } & B1 & - & - & & \\
\hline 2 & & & B2 & $60.23^{\circ}$ & {$\left[\begin{array}{lll}-0.54 & 0.53 & 0.65\end{array}\right]$} & $60.21^{\circ}$ & {$\left[\begin{array}{lll}-0.55 & 0.53 & 0.65\end{array}\right]$} \\
\hline 3 & & & B3 & $60.00^{\circ}$ & {$\left[\begin{array}{lll}-0.70 & 0.01 & 0.71\end{array}\right]$} & $59.61^{\circ}$ & {$\left[\begin{array}{lll}-0.47 & 0.51 & 0.72\end{array}\right]$} \\
\hline 4 & & & B1 & $5.02^{\circ}$ & {$\left[\begin{array}{lll}-0.67 & 0.00 & 0.74\end{array}\right]$} & $5.51^{\circ}$ & {$\left[\begin{array}{lll}-0.48 & 0.00 & 0.88\end{array}\right]$} \\
\hline 5 & & & B2 & $60.00^{\circ}$ & {$\left[\begin{array}{lll}-0.01 & 0.70 & 0.71\end{array}\right]$} & $59.61^{\circ}$ & {$\left[\begin{array}{lll}-0.51 & 0.47 & 0.72\end{array}\right]$} \\
\hline 6 & & & B3 & $54.99^{\circ}$ & {$\left[\begin{array}{lll}-0.71 & 0.01 & 0.71\end{array}\right]$} & $54.74^{\circ}$ & {$\left[\begin{array}{lll}-0.71 & 0.05 & 0.71\end{array}\right]$} \\
\hline 7 & \multirow{6}{*}{$\left(\begin{array}{lll}1 & \overline{1} & 1\end{array}\right)$} & \multirow[t]{6}{*}{$\mathrm{CP} 2$} & B2 & $49.82^{\circ}$ & {$\left[\begin{array}{lll}-0.61 & 0.51 & 0.61\end{array}\right]$} & $52.00^{\circ}$ & {$\left[\begin{array}{lll}-0.61 & 0.52 & 0.61\end{array}\right]$} \\
\hline 8 & & & B1 & $11.21^{\circ}$ & {$\left[\begin{array}{lll}-0.69 & 0.24 & 0.69\end{array}\right]$} & $9.06^{\circ}$ & {$\left[\begin{array}{lll}-0.70 & 0.18 & 0.70\end{array}\right]$} \\
\hline 9 & & & B3 & $52.53^{\circ}$ & {$\left[\begin{array}{lll}-0.21 & 0.65 & 0.73\end{array}\right]$} & $52.41^{\circ}$ & {$\left[\begin{array}{lll}-0.21 & 0.66 & 0.72\end{array}\right]$} \\
\hline 10 & & & B2 & $50.60^{\circ}$ & {$\left[\begin{array}{lll}-0.56 & 0.46 & 0.68\end{array}\right]$} & $51.39^{\circ}$ & {$\left[\begin{array}{lll}-0.57 & 0.45 & 0.69\end{array}\right]$} \\
\hline 11 & & & B1 & $13.51^{\circ}$ & {$\left[\begin{array}{lll}-0.06 & 0.55 & 0.84\end{array}\right]$} & $12.83^{\circ}$ & {$\left[\begin{array}{lll}-0.06 & 0.47 & 0.88\end{array}\right]$} \\
\hline 12 & & & B3 & $57.42^{\circ}$ & {$\left[\begin{array}{llll}-0.20 & 0.66 & 0.72\end{array}\right]$} & $57.67^{\circ}$ & {$\left[\begin{array}{lll}-0.18 & 0.66 & 0.73\end{array}\right]$} \\
\hline 13 & \multirow{6}{*}{$\left(\begin{array}{ll}1 & 11\end{array}\right)$} & \multirow[t]{6}{*}{$\mathrm{CP} 3$} & B1 & $13.51^{\circ}$ & {$\left[\begin{array}{lll}-0.55 & 0.06 & 0.84\end{array}\right]$} & $12.83^{\circ}$ & {$\left[\begin{array}{lll}-0.47 & 0.06 & 0.88\end{array}\right]$} \\
\hline 14 & & & B3 & $50.60^{\circ}$ & {$\left[\begin{array}{lll}-0.46 & 0.56 & 0.68\end{array}\right]$} & $51.39^{\circ}$ & {$\left[\begin{array}{lll}-0.45 & 0.57 & 0.69\end{array}\right]$} \\
\hline 15 & & & B2 & $55.57^{\circ}$ & {$\left[\begin{array}{lll}-0.66 & 0.24 & 0.71\end{array}\right]$} & $58.85^{\circ}$ & {$\left[\begin{array}{lll}-0.67 & 0.25 & 0.70\end{array}\right]$} \\
\hline 16 & & & B1 & $16.22^{\circ}$ & {$\left[\begin{array}{lll}-0.68 & 0.26 & 0.68\end{array}\right]$} & $16.04^{\circ}$ & {$\left[\begin{array}{llll}-0.70 & 0.18 & 0.70\end{array}\right]$} \\
\hline 17 & & & B3 & $51.38^{\circ}$ & {$\left[\begin{array}{lll}-0.64 & 0.41 & 0.64\end{array}\right]$} & $51.02^{\circ}$ & {$\left[\begin{array}{lll}-0.65 & 0.38 & 0.65\end{array}\right]$} \\
\hline 18 & & & B2 & $50.71^{\circ}$ & {$\left[\begin{array}{llll}-0.67 & 0.26 & 0.70\end{array}\right]$} & $51.79^{\circ}$ & {$\left[\begin{array}{lll}-0.65 & 0.28 & 0.70\end{array}\right]$} \\
\hline 19 & \multirow{6}{*}{$(11 \overline{1})$} & \multirow[t]{6}{*}{$\mathrm{CP} 4$} & B3 & $52.53^{\circ}$ & {$\left[\begin{array}{lll}-0.65 & 0.21 & 0.73\end{array}\right]$} & $52.41^{\circ}$ & {$\left[\begin{array}{lll}-0.66 & 0.21 & 0.72\end{array}\right]$} \\
\hline 20 & & & B2 & $57.42^{\circ}$ & {$\left[\begin{array}{lll}-0.66 & 0.20 & 0.72\end{array}\right]$} & $57.67^{\circ}$ & {$\left[\begin{array}{lll}-0.66 & 0.18 & 0.73\end{array}\right]$} \\
\hline 21 & & & B1 & $19.11^{\circ}$ & {$\left[\begin{array}{lll}-0.21 & 0.00 & 0.98\end{array}\right]$} & $18.15^{\circ}$ & {$\left[\begin{array}{lll}-0.29 & 0.00 & 0.96\end{array}\right]$} \\
\hline 22 & & & B3 & $50.71^{\circ}$ & {$\left[\begin{array}{lll}-0.26 & 0.67 & 0.70\end{array}\right]$} & $51.79^{\circ}$ & {$\left[\begin{array}{lll}-0.28 & 0.65 & 0.70\end{array}\right]$} \\
\hline 23 & & & B2 & $55.57^{\circ}$ & {$\left[\begin{array}{lll}-0.24 & 0.66 & 0.71\end{array}\right]$} & $56.85^{\circ}$ & {$\left[\begin{array}{lll}-0.25 & 0.67 & 0.70\end{array}\right]$} \\
\hline 24 & & & B1 & $19.08^{\circ}$ & {$\left[\begin{array}{lll}-0.17 & 0.00 & 0.99\end{array}\right]$} & $17.59^{\circ}$ & {$\left[\begin{array}{lll}-0.11 & 0.00 & 0.99\end{array}\right]$} \\
\hline
\end{tabular}



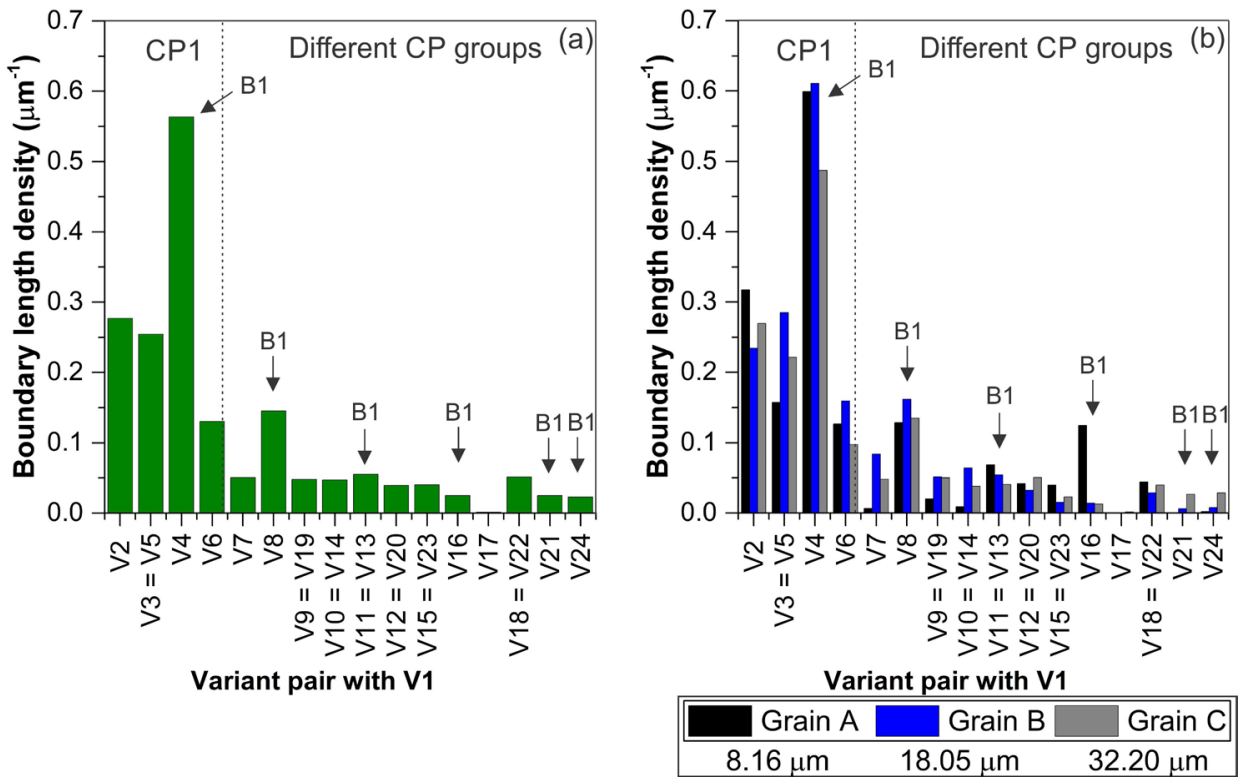

Figure 7. Grain boundary density distribution taking the variant 1 as reference for air-quenching treatment: (a) complete map and (b) grains $\mathrm{A}, \mathrm{B}$ and $\mathrm{C}$ indicated Figure 3 . Deviation: $3^{\circ}$.

belonging to the same Bain group were preferentially formed; consequently, variant selection occurred during the martensitic transformation. In addition, a higher grain boundary length density was found for the CP1. Therefore, the intervariant boundary was concentrated in the same Bain group and $\mathrm{CP}$ group. The variant selection of the same Bain group causes the formation of low angle grain boundaries; thus it does not improve the grain refinement of martensitic microstructures ${ }^{12,19,38,39}$. Studies ${ }^{19,39}$ have reported that the driving force of austenite transformation is a determining factor for the modification of variant selection from the same Bain group to different Bain groups or CP groups, which also cause martensitic/bainite grain refinement. Wu et al. ${ }^{39}$ observed that the variant group in a single grain changes from the same Bain group to different Bain groups as the average prior austenite grain size decreases from $15 \mu \mathrm{m}$ up to $6.4 \mu \mathrm{m}$. In this study, the decrease of prior austenite grain size in the same air-quenching condition did not affect the variant selection, consequently, a large boundary length density of $\mathrm{V} 1 / \mathrm{V} 4$ pair was observed for grain diameter varying from $8.16 \mu \mathrm{m}$ up to $32.20 \mu \mathrm{m}$.

Fig. 8 provides a detailed view of the grain $\mathrm{C}$ reconstructed using the G-T model, previously displayed in Figure 2 and Figure 3. The crystallographic analysis of austenite grain was carried out in regions 1 and 2 as shown in Figure $8 \mathrm{~b}$ since these regions are delimited by a grain boundary of $9^{\circ}$. The white and black lines in Figure 8 represent sub-block boundaries $\left(5.51^{\circ}<\overline{6} \quad 0 \quad 11>\right.$ with deviation $\left.<3^{\circ}\right)$ and block or packet boundaries with misorientation higher than $9^{\circ}$, respectively. These values were adopted considering the misorientation of V1/V4 and V1/V8 pairs. The blocks showed variant pairs belonging to the same Bain group forming sub-blocks, as mentioned above and previously reported for low-carbon steels ${ }^{35,36}$. Inside the blocks, a higher fraction of $5.51^{\circ}<\overline{6} 011>$ rotation angle and orientation scattering can be observed. In addition, the intervariant boundaries were sinuous, indicating a lower level of acicularity. Variant pairs belonging to different $\mathrm{CP}$ groups can be seen in region 1 . In region 2, the larger blocks presented mainly the variant pairs V19 - V22, V20 - V23 and V21 - V24, which compose the CP4 group. As stated in $\operatorname{Ref}^{34}$, the formation of the six variants inside a packet reduces the shape strain of martensitic transformation. In addition, small blocks showed one variant, i.e. V9 and V24. The results agree with the conclusion that variants belonging to the same Bain group were preferentially formed. The sub-blocks formation occurs when the shape strain of martensitic transformation is plastically accommodated ${ }^{19}$. Note that the individual data points in the $\{001\}$ pole figures were concentrated close to the ideal variant orientations according to average OR, which agrees with the conclusion that the average OR of AISI 420 steel was closer to the G-T model. In addition, it can be also observed a data points spread from ideal variant orientations $\mathrm{S}^{36,40}$.

The KAM maps of the samples after air-quenching, single tempering and double tempering treatments are shown in Figure 9. The single tempering and double tempering treatments did not cause a significant difference in KAM values as compared with the air-quenching treatment. The average $\mathrm{KAM}$ values were $2.65^{\circ}, 2.64^{\circ}$ and $2.58^{\circ}$ for the samples after air-quenching, single tempering and double tempering treatments, respectively. According to TEM studies $^{21,23}$, the substructure of samples tempered at $300^{\circ} \mathrm{C}$ is similar to the quenching condition consisting of dislocated lath martensite. These founds indicate that the changes in the microstructure that occurred during the single tempering and double tempering could not be observed by EBSD.

Figure 10 shows the potentiostatic polarization curves of the samples after air-quenching, single tempering and double tempering treatments. Figure 10 also brings the correlation between hardness and $\mathrm{E}_{\mathrm{pit}}$. The $\mathrm{E}_{\text {corr }}$ and $\mathrm{E}_{\mathrm{pit}}$ values are given in Table 3. The undissolved $\mathrm{M}_{23} \mathrm{C}_{6}$ carbides during the air- 

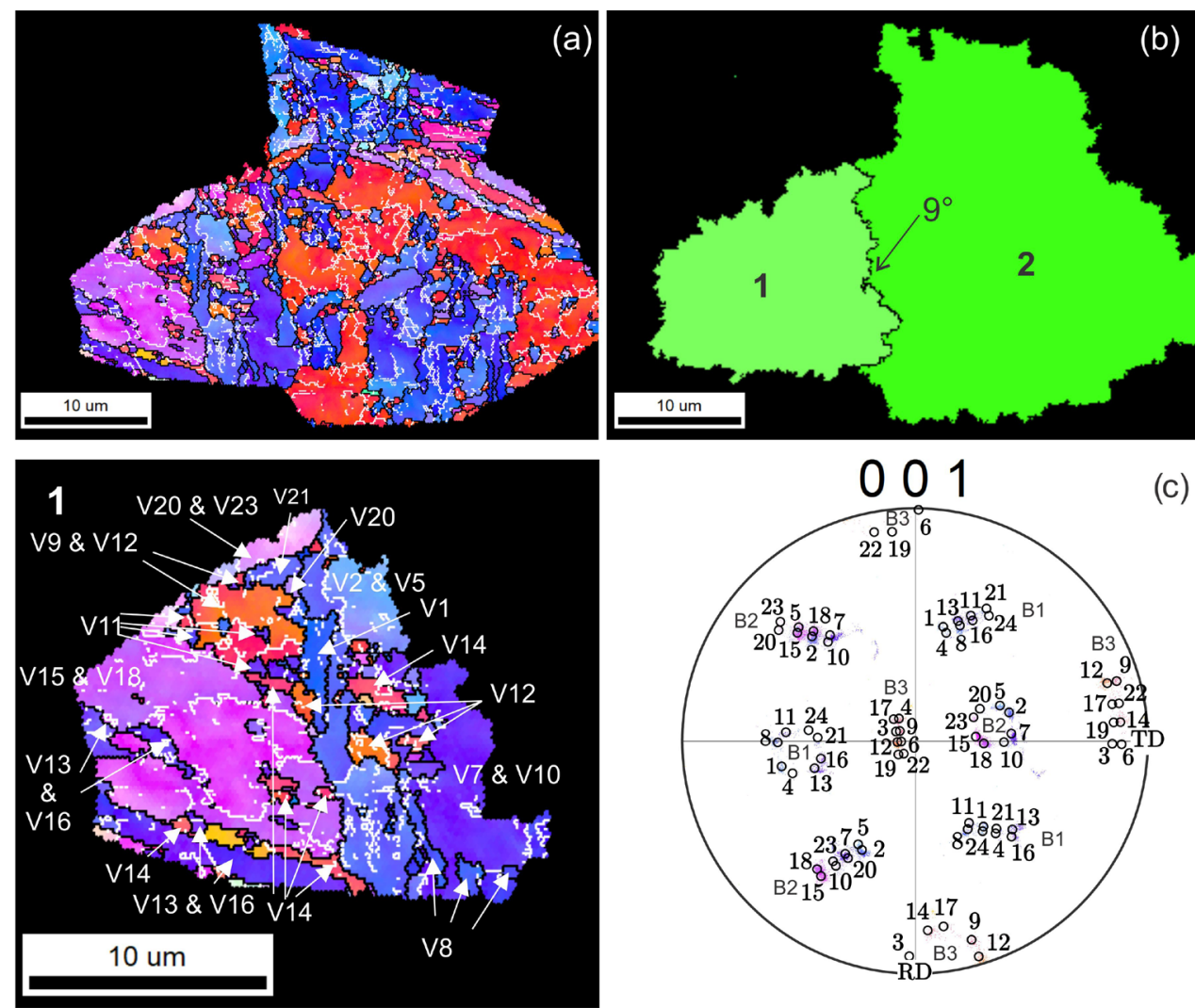

(c)
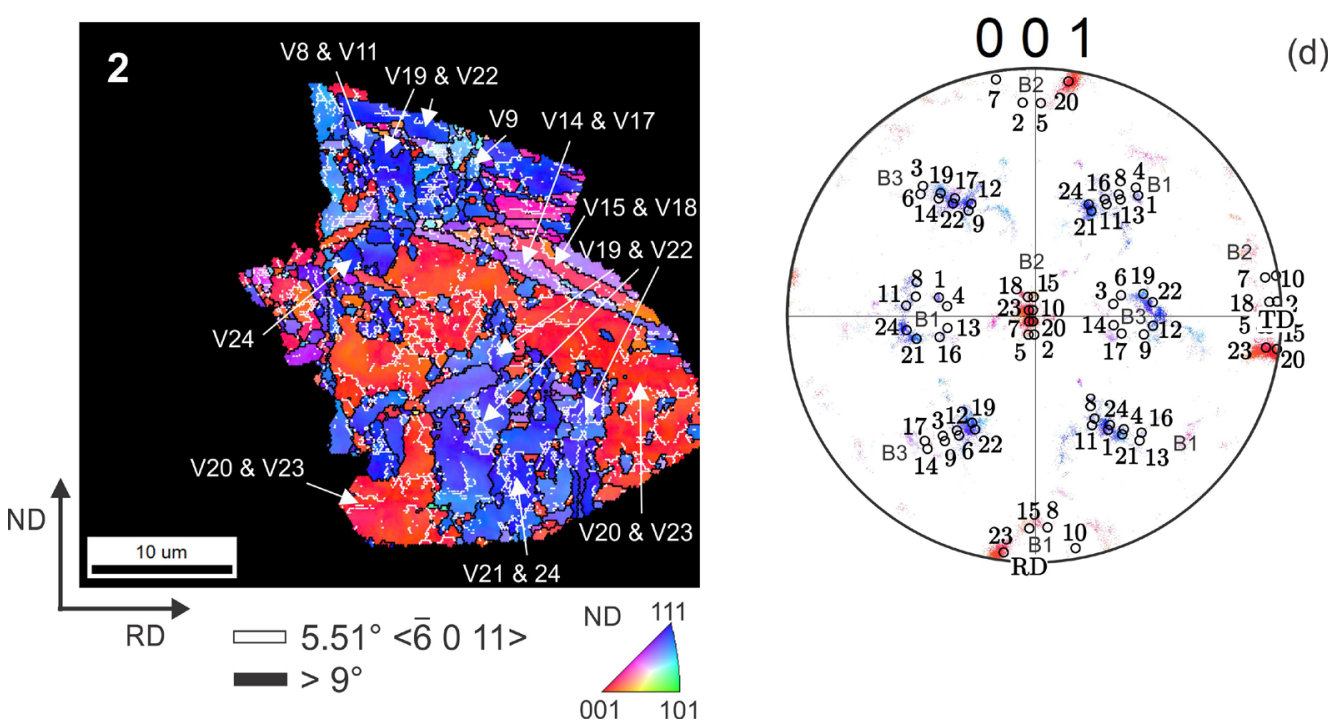

(d)

Figure 8. Detailed view of the grain $\mathrm{C}$ reconstructed using G-T model, previously displayed in Figure 2 and Figure 3. (a) IPF overlaps the corresponding image quality map of martensite and (b) IPF of Austenite. IPF and $\{100\}$ pole figures (experimental and calculated): (c) Region 1 and (d) Region 2 of reconstructed austenite grain.

quenching treatment remained in the martensitic matrix after the single and double tempering as mentioned above, thus the tempered carbides formed at $180^{\circ} \mathrm{C}$ can be considered one of the factors that affected the corrosion resistance in this study. From Figure 10 and Table 3, it can be observed that the samples showed a passive region followed by pitting at the high potential in $3.5 \mathrm{wt} \% \mathrm{NaCl}$ solution for all analyzed conditions. The corrosion behavior showed practically not much difference due to the low temperature of single and double tempering treatments $\left(180^{\circ} \mathrm{C}\right)$. High hardness and pitting corrosion resistance are properties required in the cutlery application. The single tempering showed hardness close to air-quenching treatment and did not impair the pitting corrosion resistance. The $\mathrm{E}_{\mathrm{pit}}$ values were $0.154(0.001) \mathrm{mV} / \mathrm{SCE}$ and $0.167(0.009) \mathrm{mV} / \mathrm{SCE}$ for the air-quenching and single tempering treatments, 
Table 3. Potentiodynamic polarization test results.

\begin{tabular}{lccc}
\hline & $\mathrm{E}_{\text {corr }}(\mathrm{mV} / \mathrm{SCE})$ & $\mathrm{I}_{\text {corr }}\left(\mathrm{A} / \mathrm{cm}^{2} \times 10^{-9}\right)$ & $\mathrm{E}_{\text {pit }}(\mathrm{mV} / \mathrm{SCE})$ \\
\hline Air-quenching & $-0.170(0.011)$ & $5.22(2.28)$ & $0.154(0.001)$ \\
\hline Single tempering & $-0.230(0.003)$ & $10.5(7.67)$ & $0.167(0.009)$ \\
\hline Double tempering & $-0.179(0.009)$ & $4.63(4.10)$ & $0.131(0.017)$ \\
\hline
\end{tabular}
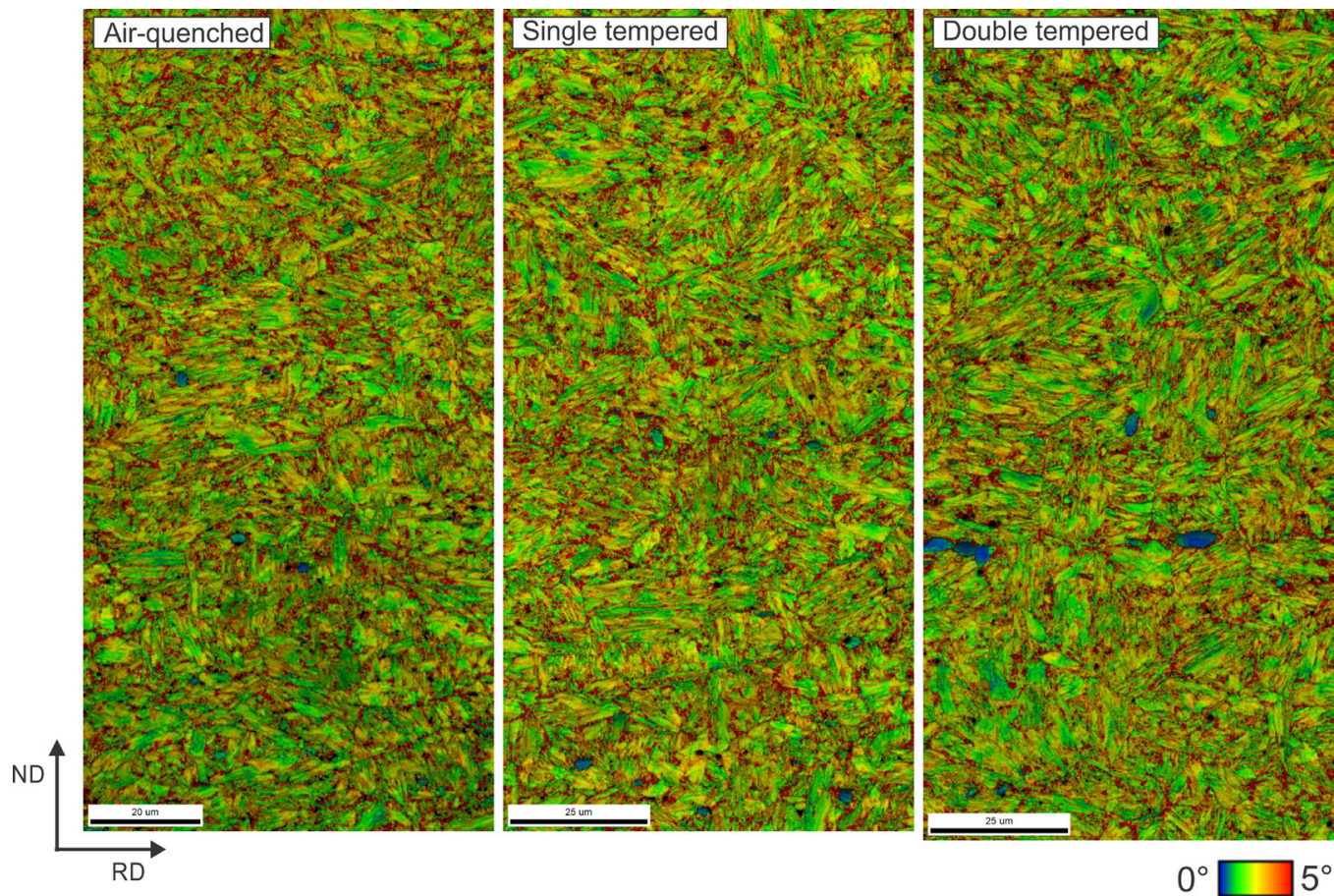

Figure 9. KAM maps of the samples after air-quenching, single tempering and double tempering treatments.

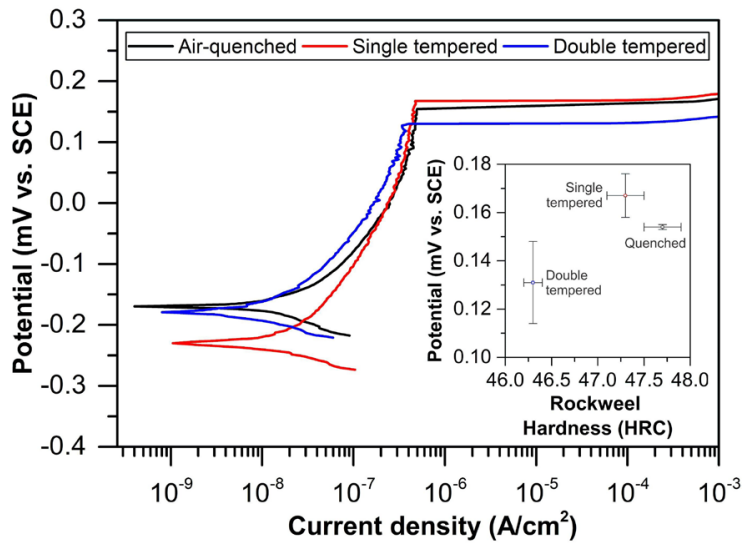

Figure 10. Potentiodynamic polarization curves of the samples after air-quenching, single tempering and double tempering treatments and the correlation between hardness and $\mathrm{E}_{\mathrm{pit}}$.

respectively. This result can be attributed to the stress relief during tempering. The tensile stress in the surface decreases the mechanical integrity of the passive film, consequently, the pitting susceptibility ${ }^{41}$.

In contrast, the double tempering treatment did not improve the pitting corrosion resistance, i. e. the $\mathrm{E}_{\text {pit }}$ obtained after double tempering was $0.131(0.017) \mathrm{mV} / \mathrm{SCE}$. The decrease of $\mathrm{E}_{\mathrm{pit}}$ has been reported after tempering temperatures up to $300^{\circ} \mathrm{C}^{21-23}$. The nucleation of $\mathrm{M}_{3} \mathrm{C}$ carbides occurs uniformly in the matrix and the low diffusion rate does not cause accentuated growth. Therefore, the $\mathrm{M}_{3} \mathrm{C}$ carbide size may have slightly increased after the double tempering leading to a decrease of $\mathrm{E}_{\mathrm{pit}}$ value $^{26}$. The $\mathrm{M}_{3} \mathrm{C}$ carbides have the same $\mathrm{Cr}$ content as compared with the matrix, thus the $\mathrm{Cr}$ depletion was not promoted by the precipitation of $\mathrm{M}_{3} \mathrm{C}$ carbides ${ }^{22,23}$. The reduction in $\mathrm{E}_{\text {pit }}$ after tempering due to the precipitation of $\mathrm{M}_{3} \mathrm{C}$ carbides may have its cause in the distortion close to the carbides/matrix interface that renders this region preferential sites for pitting ${ }^{22}$. In addition, the hardness was reduced after the double tempering treatment. Therefore, double tempering treatment reduced hardness and did not improve pitting corrosion resistance. In the light of these results, it can be concluded that the production costs can be reduced by performing only the air-quenching and single tempering processes. The $\mathrm{I}_{\text {corr }}$ values were significantly low and close as compared with single and double tempering treatments. Additionally, the double tempered sample showed the highest $\mathrm{E}_{\text {corr }}$ value, suggesting a higher propensity towards oxidation ${ }^{21}$. However, the AISI 420 steel in aerated $3.5 \mathrm{wt} \% \mathrm{NaCl}(\mathrm{pH}=6)$ solution showed pitting corrosion.

\section{Conclusions}

The martensitic microstructure of AISI 420 steel after airquenching treatment and the corrosion resistance dependence 
with the single and double tempering treatment at $180^{\circ} \mathrm{C}$ were investigated. The main results can be summarized as follows:

- The average OR of AISI 420 with respect to austenite matrix was $\varphi_{1}=3.6^{\circ}, \Phi=46.0^{\circ}, \varphi_{2}=6.2^{\circ}$ in the area mapped, thus closer to the G-T OR model with a deviation of $2.6^{\circ}$.

- The blocks showed variant pairs belonging to the same Bain group forming sub-blocks with misorientation $5.51^{\circ}<\overline{6} \quad 011>$ (V1/V4 pair), consequently, the shape strain was plastically accommodated and the variant selection occurred during the martensitic transformation. The intervariant boundary was concentrated in the same Bain group and CP group.

- Prior austenite grain diameter varying from $8.16 \mu \mathrm{m}$ up to $32.20 \mu \mathrm{m}$ showed a large boundary length density of V1/V4 pair, indicating that the different prior austenite grain size in the microstructure did not influence the variant selection in the same airquenching condition.

- The KAM values were significantly close for airquenching, single tempering and double tempering treatments, suggesting that the microstructural changes in the two last processes cannot be observed by EBSD.

- The corrosion behavior showed practically not much difference due to the low temperature of single and double tempering treatments $\left(180^{\circ} \mathrm{C}\right)$. The single tempering showed hardness close to air-quenching treatment and did not impair the pitting corrosion resistance. The double tempering treatment did not improve the pitting corrosion resistance and the hardness was reduced. Thus, the production costs can be reduced by performing only the airquenching and single tempering processes for cutlery application.

\section{Acknowledgments}

The authors acknowledge the Aperam South America, Universidade Federal do Espírito Santo, FAPES and CNPQ. Ariane Neves de Moura is also grateful to the FAPES for the $\mathrm{PhD}$ scholarship granted during the period of this work (process no. 42/2018, Diário Oficial 01.01.0001).

\section{References}

1. Davis JR. Metalurgy and properties of wrought stainless steel. In: ASM International. ASM Specialty Handbook. Materials Park, OH: ASM International; 1996. p. 13-49.

2. Garrison WM, Amuda MOH. Stainless steels: martensitic. In: Hashmi S. Reference module in materials science and materials engineering. Amsterdam: Elsevier; 2017. p. 1-9.

3. Bhadeshia H, Honeycombe R. Steels: microstructure and properties. USA: Elsevier; 2017. Formation of Martensite. p. 135-77.

4. Kelly PM. Crystallography of martensite transformations in steels. In: Pereloma E, Edmonds DV, editors. Phase transformations in steels. Sawston, Reino Unido: Woodhead Publishing Limited; 2012. p. 3-33.

5. Morsdorf L, Tasan CC, Ponge D, Raabe D. 3D structural and atomic-scale analysis of lath martensite: effect of the transformation sequence. Acta Mater. 2015;95:366-77.
6. Suikkanen PP, Cayron C, DeArdo AJ, Karjalainen LP. Crystallographic analysis of martensite in $0.2 \mathrm{C}-2.0 \mathrm{Mn}-1.5 \mathrm{Si}-0.6 \mathrm{Cr}$ steel using EBSD. J Mater Sci Technol. 2011;27(10):920-30.

7. Kurdjumow G, Sachs G. Over the mechanisms of steel hardening. Z Phys. 1930;64(5-6):325-43.

8. Greninger AB, Troiano AR. The mechanism of Martensite formation. JOM. 1949;1(9):590-8.

9. Wassermann G. Einfluß der $\alpha-\gamma$-Umwandlung eines irreversiblen Nickelstahls auf Kristallorientierung und Zugfestigkeit. Arch Eisenhuttenwes. 1933;6(8):347-51.

10. Miyamoto G, Takayama N, Furuhara T. Accurate measurement of the orientation relationship of lath martensite and bainite by electron backscatter diffraction analysis. Scr Mater. 2009;60(12):1113-6.

11. Miyamoto G, Iwata N, Takayama N, Furuhara T. Mapping the parent austenite orientation reconstructed from the orientation of martensite by EBSD and its application to ausformed martensite. Acta Mater. 2010;58(19):6393-403.

12. Wang XL, Ma XP, Wang ZQ, Subramanian SV, Xie ZJ, Shang $\mathrm{CJ}$, et al. Carbon microalloying effect of base material on variant selection in coarse grained heat affected zone of X80 pipeline steel. Mater Charact. 2019;149:26-33.

13. Abbasi M, Nelson TW, Sorensen CD, Wei L. An approach to prior austenite reconstruction. Mater Charact. 2012;66:1-8.

14. Zilnyk KD, Almeida DR Jr, Sandim HRZ, Rios PR, Raabe D. Misorientation distribution between martensite and austenite in Fe-31 wt\%Ni-0.01 wt\%C. Acta Mater. 2018;143:227-36.

15. Almeida DR Jr, Zilnyk KD, Raabe D, Sandim HRZ. Reconstructing the austenite parent microstructure of martensitic steels: a case study for reduced-activation Eurofer steels. J Nucl Mater. 2019;516:185-93.

16. Wu BB, Wang ZQ, Wang XL, Xu WS, Shang CJK, Misra RD. Toughening of martensite matrix in high strength low alloy steel: regulation of variant pairs. Mater Sci Eng A. 2019;759:430-6.

17. Wang XL, Wang ZQ, Dong LL, Shang CJ, Ma XP, Subramanian $\mathrm{SV}$. New insights into the mechanism of cooling rate on the impact toughness of coarse grained heat affected zone from the aspect of variant selection. Mater Sci Eng A. 2017;704:448-58.

18. Beladi H, Rohrer GS, Rollett AD, Tari V, Hodgson PD. The distribution of intervariant crystallographic planes in a lath martensite using five macroscopic parameters. Acta Mater. 2014;63:86-98.

19. Takayama N, Miyamoto G, Furuhara T. Effects of transformation temperature on variant pairing of bainitic ferrite in low carbon steel. Acta Mater. 2012;60(5):2387-96.

20. Sanz L, Pereda B, López B. Validation and analysis of the parameters for reconstructing the austenite phase from martensite electron backscatter diffraction data. Metall Mater Trans, A Phys Metall Mater Sci. 2017;48(11):5258-72.

21. Bonagani SK, Bathula V, Kain V. Influence of tempering treatment on microstructure and pitting corrosion of $13 \mathrm{wt} \%$ Cr martensitic stainless steel. Corros Sci. 2018;131:340-54.

22. Lu S-Y, Yao K-F, Chen Y-B, Wang M-H, Ge X-Y. Influence of heat treatment on the microstructure and corrosion resistance of 13 Wt Pct Cr-type martensitic stainless steel. Metall Mater Trans, A Phys Metall Mater Sci. 2015;46(12):6090-102.

23. Lu S-Y, Yao K-F, Chen Y-B, Wang M-H, Liu X, Ge X. The effect of tempering temperature on the microstructure and electrochemical properties of a 13wt.\% Cr-type martensitic stainless steel. Electrochim Acta. 2015;165:45-55.

24. Tao X, Gu J, Han L. Characterization of precipitates in X12CrMoWVNbN10-1-1 steel during heat treatment. J Nucl Mater. 2014;452(1-3):557-64.

25. Zhang M, Huang CB, Zeng WM, Fu RY, Li L. Recrystallization behavior of $0.11 \%$ Ti-added complex phase steel during hot compression. Mater Sci Forum. 2013;762:128-33.

26. Chakraborty G, Das CR, Albert SK, Bhaduri AK, Thomas Paul V, Panneerselvam G, et al. Study on tempering behaviour of AISI 410 stainless steel. Mater Charact. 2015;100:81-7. 
27. Isfahany AN, Saghafian H, Borhani G. The effect of heat treatment on mechanical properties and corrosion behavior of AISI420 martensitic stainless steel. J Alloys Compd. 2011;509(9):3931-6.

28. Cayron C. ARPGE : a computer program to automatically reconstruct the parent grains from electron backscatter diffraction data. J Appl Cryst. 2007;40(6):1183-8.

29. Bachmann F, Hielscher R, Schaeben H. Texture analysis with MTEX - free and open source software toolbox. Diffus Defect Data Solid State Data Pt B Solid State Phenom. 2010;160:63-8.

30. ASTM International. E8/E8M - 16a Standard Test Methods for Tension Testing of Metallic Materials. West Conshohocken: ASTM International; 2016.

31. García de Andrés C, Caruana G, Alvarez L. Control of M23C6 carbides in $0.45 \mathrm{C}-13 \mathrm{Cr}$ martensitic stainless steel by means of three representative heat treatment parameters. Mater Sci Eng A. 1998;241(1-2):211-5.

32. Barlow LD, Du Toit M. Effect of austenitizing heat treatment on the microstructure and hardness of martensitic stainless steel AISI 420. J Mater Eng Perform. 2012;21(7):1327-36.

33. Calliari I, Zanesco M, Dabalà M, Brunelli K, Ramous E. Investigation of microstructure and properties of a Ni-Mo martensitic stainless steel. Mater Des. 2008;29(1):246-50.

34. Morito S, Tanaka H, Konishi R, Furuhara T, Maki T. The morphology and crystallography of lath martensite in $\mathrm{Fe}-\mathrm{C}$ alloys. Acta Mater. 2003;51(6):1789-99.
35. Morito S, Huang X, Furuhara T, Maki T, Hansen N. The morphology and crystallography of lath martensite in alloy steels. Acta Mater. 2006;54(19):5323-31.

36. Kitahara H, Ueji R, Tsuji N, Minamino Y. Crystallographic features of lath martensite in low-carbon steel. Acta Mater. 2006;54(5):1279-88

37. Abbasi M, Kim D-I, Nelson TW, Abbasi M. EBSD and reconstruction of pre-transformation microstructures, examples and complexities in steels. Mater Charact. 2014;95:219-31.

38. Stormvinter A, Miyamoto G, Furuhara T, Hedström P, Borgenstam A. Effect of carbon content on variant pairing of martensite in Fe-C alloys. Acta Mater. 2012;60(20):7265-74.

39. Wu BB, Wang XL, Wang ZQ, Zhao JX, Jin YH, Wang CS, et al. New insights from crystallography into the effect of refining prior austenite grain size on transformation phenomenon and consequent mechanical properties of ultra-high strength low alloy steel. Mater Sci Eng A. 2019;745:126-36.

40. Kitahara H, Ueji R, Ueda M, Tsuji N, Minamino Y. Crystallographic analysis of plate martensite in Fe-28.5 at.\% Ni by FE-SEM/ EBSD. Mater Charact. 2005;54(4-5):378-86.

41. Chastell D, Doig P, Flewitt PEJ, Ryan K. The influence of stress on the pitting susceptibility of a $12 \% \mathrm{CrMoV}$ martensitic stainless steel. Corros Sci. 1979;19(5):335-41. 